\title{
Rates of responding in the pigeon generated by simple and complex schedules which provide the same rates of reinforcement
}

\author{
F. K. McSWEENEY and D. A. DERICCO \\ Washington State University, Pullman, Washington 99163
}

\begin{abstract}
Four pigeons pecked for food reinforcement on variable interval 1-min schedules and on the variable-interval 1-min components of multiple, concurrent, and pseudoconcurrent schedules. The pseudoconcurrent schedule provided only one schedule of reinforcement; but, any reinforcer could be collected by responding on either of two keys. The rate of responding generated by the variable interval schedule was not greater than the rates of responding generated by the components of the complex schedules. But, the rate of reinforcement obtained from the variable interval schedule was greater than the rates of reinforcement obtained from the components of the multiple schedule. These results may contradict the equation proposed by Herrnstein (1970). The equation predicts that the rate of responding generated by a schedule of reinforcement will be greater when the schedule appears alone, than when it appears as one component of a complex schedule.
\end{abstract}

Herrnstein (1970) proposed an equation to describe the rates of responding generated by several schedules of reinforcement. This equation has received extensive empirical support. But one of its most interesting predictions has not been confirmed. The equation predicts that the rate of responding generated by a simple schedule of reinforcement will be greater than or equal to the rate of responding generated by the same schedule when it appears as one component of a concurrent or multiple schedule. A simple schedule of reinforcement provides reinforcement contingent on only one response. A concurrent schedule provides two or more simple schedules of reinforcement. The subject can respond on any schedule at any time. A multiple schedule also provides two or more simple schedules. But, the experimenter, not the subject, determines which schedule is available.

Herrnstein's theory appears in Equation 1.

$$
P_{1}=\frac{k R_{1}}{R_{1}+m R_{2}+R_{0}} .
$$

$P_{1}$ is the rate of responding generated by a rate of reinforcement equal to $R_{1} ; R_{2}$ is the rate of reinforcement generated by a second response $\left(\mathbf{P}_{2}\right)$, if one is available; and $\mathrm{k}, \mathrm{m}$, and $\boldsymbol{R}_{0}$ are parameters which are estimated from the data, with certain restrictions. $\mathbf{M}$ equals 1.0 for concurrent schedules, but $0 \leqslant m \leqslant 1.0$ for multiple schedules (Herrnstein, 1970). $\mathrm{K}$ is the subject's asymptotic rate of responding. $P_{1}$ would

The authors wish to thank K. Kearney and G. Grammer for their assistance in running the subjects. Reprints may be obtained from F. K. McSweeney, Department of Psychology, Washington State University, Pullman, Washington, 99163. This research was supported by NIMH Grant MH 28192-01 to F. K. McSweeney. equal $k$ if the subject obtained all of its reinforcement from $R_{1} . K$ is measured in responses per time unit. Its size varies only with the subject and with the topographical form of the response. It does not change with changes in reinforcement (Herrnstein, 1974). $R_{0}$ is the rate of reinforcement which the subject obtains spontaneously, without responding. It is measured in reinforcers per time unit (Herrnstein, 1974). Its value may change as an orderly function of several variables. For example, Herrnstein and Loveland (1974) argued that the value of $R_{0}$ should increase relative to $R_{1}$ and $R_{2}$, and perhaps absolutely, as the subject's need for the programmed reinforcer decreases. They assumed that the subjects turn increasingly to other sources of reinforcement as they become satiated for the programmed one.

Equation 1 predicts that the rate of responding generated by a schedule of reinforcement will be greater when that schedule appears alone than when it appears as one component of a complex schedule. The rate of responding generated by $R_{1}$ will depend on the size of $k, m, R_{0}$, and $R_{2}$. $K$ and $R_{0}$ should not change when a simple schedule of reinforcement becomes one component of a complex schedule. $\mathbf{K}$ will remain constant unless the form of the response required for reinforcement changes. $R_{0}$ will remain constant unless factors such as the subject's need for the programmed reinforcer changes. But $R_{2}$ will be larger for a component of most concurrent or multiple schedules than it will be for the same schedule appearing alone. $R_{2}=0$ for simple schedules of reinforcement. But $R_{2}$ will be a positive number for concurrent or multiple schedules if the alternative component schedule provides any reinforcement. A positive $R_{2}$ will increase the size of the denominator of Equation 1, unless $\mathbf{m}=\mathbf{0}$. The larger size of the denominators of the 
equations for the components of complex schedules will decrease the rate of responding generated by $R_{1}$ for these schedules.

This prediction has not been tested for concurrent schedules. The prediction has been tested for multiple schedules, but the results have been inconsistent. One study failed to confirm it. Pigeons responded on variable interval 30-sec (VI 30-sec), VI 180-sec, multiple variable interval $30-\mathrm{sec}$ variable interval $30-\mathrm{sec}$ (mult VI 30-sec VI 30-sec), and mult VI 180-sec VI 180sec schedules (Spealman \& Gollub, 1974). But, there were no consistent differences between the rates of responding generated by the simple schedules and the components of the complex schedules which provided the same rates of reinforcement.

Four studies have supported the prediction, but two are unpublished and the results of the other two are not conclusive. Terrace (cited in Herrnstein, 1970) found a decrease in the rate of responding when pigeons moved from a VI 1-min to a mult VI 1-min VI 1-min schedule. Carr and Reynolds (cited in Staddon, 1974) found that subjects paused longer immediately after reinforcers delivered on a multiple fixed interval 4.5 -min fixed interval $4.5-\mathrm{min}$ schedule (mult FI 4.5-min FI 4.5-min) than on a fixed interval 4.5-min schedule (FI 4.5-min). Longer postreinforcement pauses should generate lower response rates. Bloomfield (1967) reported that pigeons responded at a higher rate on a VI 1-min schedule than they did on a VI 1-min component of a mult VI 1-min VI 1-min schedule. But the components of the multiple schedule alternated on successive days. Thus, the results may not apply to multiple schedules which present both components in a single session. Finally, DeVilliers (1972) reported that rats , responded faster on a random interval $15-\mathrm{sec}$ (RI 15-sec) avoidance schedule than they did on either component of mult RI 15-sec RI 15-sec avoidance schedule. However, each schedule was presented only once. The rate of responding generated by the RI schedule should have been replicated after the multiple schedule had been conducted. Replicating the RI schedule would help to distinguish fluctuations in the rate of responding which occur over time from changes in the rate of responding produced by the changes in the schedule.

The present experiment examined the rate of responding generated by a variable interval schedule when that schedule appeared alone, and when it appeared as one component of a complex schedule. It compared the rates generated by the simple schedule to the rates generated by the components of standard concurrent and multiple schedules. And it compared simple schedule responding to the rate generated by a pseudoconcurrent schedule. The pseudoconcurrent schedule provided only one rate of reinforcement, but the subject could collect any reinforcer by responding on either of two response manipulanda. A standard concurrent schedule programs two independent rates of reinforcement. The subject obtains the reinforcers programmed by one schedule by responding on one manipulandum. It obtains the reinforcers programmed by the second schedule by responding on a second manipulandum.

The pseudoconcurrent schedule held the total rate of reinforcement constant from the simple to the complex schedules. The total of reinforcement may double when a subject moves from a VI x-min schedule to a standard concurrent VI x-min VI x-min schedule. For example, most subjects collect approximately 60 reinforcers per hour from a VI 1-min or from a mult VI 1-min VI 1-min schedule. But, they may obtain as many as 120 reinforcers per hour from a standard concurrent VI 1-min VI 1-min schedule. They may obtain 60 reinforcers from each of the two component schedules. The pseudoconcurrent schedule held the total rate of reinforcement constant. Only one VI 1-min schedule provided reinforcers. Thus, only 60 reinforcers could be obtained in 1 hour, even though any reinforcer might be produced by a response on either manipulandum.

\section{METHOD}

\section{Subjects}

Four naive homing pigeons, maintained at $80 \%$ to $85 \%$ of their free-feeding body weights, served as subjects.

\begin{abstract}
Apparatus
The apparatus was a standard three-key Grason-Stadler pigeon station, Model E64460, enclosed in a Grason-Stadler, Model E3125A-300, sound-attenuating chamber. Electromechanical equipment, located in another room, scheduled the experimental events.
\end{abstract}

\section{Procedure}

An autoshaping procedure (Brown \& Jenkins, 1968) was used to train all subjects to peck the center key which was illuminated with green light. Then the subjects responded on a VI 15-sec schedule of reinforcement. The schedule was changed to a VI 30-sec schedule when a steady rate of responding developed. The V1 30 -sec schedule continued until responding stabilized again. It was followed by a series of schedules of reinforcement. The schedules used, and the number of sessions for which each schedule was available, appear in Table 1 in order of presentation.

Table 1

Schedules of Reinforcement and the Number of Sessions for Which Each Schedule Was Available in Order of Presentation

Schedule Number of Sessions

VI $1-\min$ 25

mult VI $1-\min$ VI $1-$ min

VI 1-min

19

mult VI 1-min VI 1-min

22

VI 1-min

pseudo-conc VI 1-min VI 1 -min

VI 1-min

conc VI 1-min VI 1-min

26

VI 1-min 
A green light illuminated the center response key, located directly above the food magazine, during each of the VI schedules. Pecks to this key produced reinforcement and a brief feedback click. The other two keys were not illuminated. Pecks on them were ineffective: they did not produce feedback clicks or reinforcement, and they were not recorded.

Green and white lights alternated on the center key every 1.5 min during the multiple schedules. Again, pecks on this key produced reinforcement and a feedback click. The other two keys were not illuminated and pecks on them were ineffective. Reinforcers were programmed by a single VI 1-min schedule, regardless of the color of the key. Reinforcers which became available, but which were not collected during one key color were held over for collection during the next color. That is, reinforcers were collected by the next response, regardless of the color of the key when that response occurred. Reinforcers were not cancelled when the color of the key light changed; and they were not held over for the next appearance of the color in which they had become available.

A green light illuminated the center key and a white light illuminated the key located to the subject's left as it faced the magazine, during the concurrent and pseudoconcurrent schedules. Pecks to these keys produced reinforcement and a feedback click. Pecks to the other key were ineffective. Subjects were trained to peck the left key by covering the center key for the first five sessions for which each schedule was available. Reinforcers were scheduled according to a single variable interval schedule during the pseudoconcurrent schedule. Pecks on either illuminated key collected any reinforcer. Reinforcers were scheduled according to two variable interval schedules which ran independently during the concurrent schedule. Pecks on the center key collected reinforcers from one schedule; pecks on the left key collected reinforcers from the other. Each change from one key to the other initiated a 3-sec changeover delay (COD), during which no responses were reinforced, for both the concurrent and pseudoconcurrent schedules.

Sessions were conducted daily, six to seven times per week for each schedule. Sessions terminated when $\mathbf{4 0}$ reinforcers had been collected, and each reinforcer provided $5 \mathrm{sec}$ access to a magazine containing grain. Reinforcers were scheduled according to a 20 -interval series generated by a procedure outlined by Catania and Reynolds (1968, Appendix II). Each schedule was presented until responding stabilized for all subjects. Responding was considered to be stable when the rates of responding generated during the last five sessions all fell within the range of the rates of responding set by the earlier sessions. A houselight located in the upper right corner of the wall which contained the magazine, illuminated the chamber throughout the sessions.

\section{RESULTS}

Table 2 presents the rate of responding generated by each component of each schedule. All rates are the means of the rates generated over the last five sessions for which each schedule was available. The rates have been calculated as Herrnstein prescribes: overall rates have been reported for concurrent schedules, local rates, for multiple schedules (Herrnstein, 1970). Overall rates were calculated by dividing the number of responses emitted on each component of each schedule by the total session time. The time for which the magazine was presented was excluded from this and from each of the other calculations. Local rates were calculated by dividing the number of responses emitted during a component schedule by the time for which that component was available. Local rates have also been reported for the concurrent and pseudoconcurrent schedules to facilitate comparison with the rates generated by the multiple schedules. The timing of the duration of the components of these schedules began with the response which initiated a COD to that component and continued until the response that initiated a COD to the other component. The rates reported for the VI schedules are both local and overall rates. The total session time equals the time for which the component was available because there was only one component.

The rates of responding generated by the VI schedules were not consistently greater than the rates generated by the components of the complex schedules which preceded or followed them. Three of four subjects decreased their overall rates of responding during the green stimulus, when moved from the VI to the pseudoconcurrent schedule. But, only two subjects showed a decrease when the rate of responding during the green component of the pseudoconcurrent schedule was compared to the rate of

Table 2

Rate of Responding (Pecks/Minute) on Each Component of Each Schedule

\begin{tabular}{|c|c|c|c|c|c|c|c|c|c|c|c|c|}
\hline Bird & & VI & mult VIVI & VI & mult VIVI & VI & $\begin{array}{l}\text { pseudo } \\
\text { conc } \\
\text { VIVI } \\
\text { Local } \\
\text { Rates }\end{array}$ & $\begin{array}{l}\text { pseudo } \\
\text { conc } \\
\text { VIVI } \\
\text { Overall } \\
\text { Rates }\end{array}$ & VI & $\begin{array}{l}\text { conc } \\
\text { VIVI } \\
\text { Local } \\
\text { Rates }\end{array}$ & $\begin{array}{c}\text { conc } \\
\text { VIVI } \\
\text { Overall } \\
\text { Rates }\end{array}$ & VI \\
\hline 2455 & $\begin{array}{l}\text { green } \\
\text { white }\end{array}$ & 32.1 & $\begin{array}{l}30.7 \\
32.9\end{array}$ & 35.9 & $\begin{array}{l}31.3 \\
34.7\end{array}$ & 45.1 & $\begin{array}{l}48.0 \\
44.8\end{array}$ & $\begin{array}{r}.1 \\
44.7\end{array}$ & 40.9 & $\begin{array}{l}47.4 \\
39.1\end{array}$ & $\begin{array}{r}46.6 \\
.8\end{array}$ & 35.7 \\
\hline 2560 & $\begin{array}{l}\text { green } \\
\text { white }\end{array}$ & 63.6 & $\begin{array}{l}58.4 \\
56.4\end{array}$ & 61.8 & $\begin{array}{l}82.8 \\
84.6\end{array}$ & 70.8 & $\begin{array}{r}7.5 \\
82.7\end{array}$ & $\begin{array}{r}.1 \\
80.9\end{array}$ & 47.2 & $\begin{array}{l}75.1 \\
52.4\end{array}$ & $\begin{array}{l}58.9 \\
11.9\end{array}$ & 55.5 \\
\hline 2457 & $\begin{array}{l}\text { green } \\
\text { white }\end{array}$ & 34.0 & $\begin{array}{l}25.4 \\
27.1\end{array}$ & 30.4 & $\begin{array}{l}23.5 \\
33.1\end{array}$ & 27.0 & $\begin{array}{l}33.7 \\
20.5\end{array}$ & $\begin{array}{r}32.9 \\
.6\end{array}$ & 31.8 & $\begin{array}{r}67.9 \\
0.0\end{array}$ & $\begin{array}{r}67.9 \\
0.0\end{array}$ & 40.4 \\
\hline 2454 & $\begin{array}{l}\text { green } \\
\text { white }\end{array}$ & 32.7 & $\begin{array}{l}37.5 \\
39.2\end{array}$ & 28.4 & $\begin{array}{l}41.2 \\
40.6\end{array}$ & 42.9 & $\begin{array}{l}37.9 \\
34.6\end{array}$ & $\begin{array}{r}32.0 \\
5.3\end{array}$ & 31.6 & $\begin{array}{l}50.4 \\
41.2\end{array}$ & $\begin{array}{r}4.6 \\
38.1\end{array}$ & 40.9 \\
\hline mean & $\begin{array}{l}\text { green } \\
\text { white }\end{array}$ & 40.6 & $\begin{array}{l}38.0 \\
38.9\end{array}$ & 39.1 & $\begin{array}{l}44.7 \\
48.3\end{array}$ & 46.5 & $\begin{array}{l}31.8 \\
45.6\end{array}$ & $\begin{array}{l}16.3 \\
32.9\end{array}$ & 37.9 & $\begin{array}{l}60.2 \\
33.2\end{array}$ & $\begin{array}{l}44.5 \\
12.7\end{array}$ & 43.1 \\
\hline
\end{tabular}


responding during the VI schedule that followed it. Three of four subjects decreased their rates of responding when first moved from the VI to the mult VI VI schedule. But, the decrease was not replicated. Two subjects decreased and two increased their rates of responding when moved from the VI to the multiple schedule again. Subjects increased rather than decreased their rates of responding when moved from the VI to the concurrent schedule. The local rate of responding during the green stimulus increased for all four subjects, and the overall rate increased for three subjects.

Table 3 presents the rate of reinforcement obtained by responding on each component of each schedule. The rates are the means of the rates obtained over the last 5 days for which each schedule was available. Local rates have been reported for the VI and multiple schedules. Local and overall rates have been reported for the concurrent and pseudoconcurrent schedules. Local and overall rates were calculated as they were for the rates of responding, except that the number of reinforcers obtained from each schedule was substituted for the number of responses emitted. The subjects which obtained very high local rates of reinforcement from one component of the concurrent schedule rarely responded on that component schedule. Thus, reinforcement was usually available when they did respond. The large number of reinforcers collected created a very high local rate of reinforcement when divided by the small number of seconds required to collect them.

The rates of reinforcement obtained from the components of the multiple schedules signaled by the green light were consistently lower than the rates of reinforcement obtained from the VI 1-min schedules. All eight rates of reinforcement obtained from the green component of the multiple schedules were lower than the rates obtained from the VI schedules which followed them. And all eight rates obtained from the green components of the multiple schedules were lower than the rates obtained from the VI schedule which preceded them. Both differences were significant $(p=.004)$ by the binomial test (Siegel, 1956).

The rates of reinforcement obtained from the components of the concurrent and pseudoconcurrent schedules were not consistently lower than the rates obtained from the VI schedules. The overall rate of reinforcement obtained during the green stimulus did decrease for three of four subjects moved from the VI to the concurrent schedule. But the local rate of reinforcement decreased for only one subject. The overall and local rates of reinforcement obtained during the green stimulus decreased for only two subjects, when the subjects moved from the VI to the pseudoconcurrent schedule. Comparing the rates of reinforcement obtained from the components of the concurrent and pseudoconcurrent schedules to the rates of reinforcement obtained from the VI schedules which followed them yielded the same conclusion. None of the changes were statistically significant $(p \leqslant .05)$ by the binomial test.

\section{DISCUSSION}

The data do not confirm the predictions of Herrnstein's equation. The equation is contradicted by the failure to find a decrease in the overall rate of responding when subjects moved from the VI to the concurrent schedule, and by the failure to find a decrease in the local rate of responding when subjects moved from the VI to the multiple schedule. Several reasons for the failure of these predictions will be considered.

First, the increase in the total rate of reinforcement which occurred when subjects moved from the VI to the concurrent schedule did not produce

Table 3

Rate of Reinforcement (Reinforcers/Hour) on Each Component of Each Schedule

\begin{tabular}{|c|c|c|c|c|c|c|c|c|c|c|c|c|}
\hline Bird & & VI & mult VIVI & VI & mult VIVI & VI & $\begin{array}{l}\text { pseudo } \\
\text { conc } \\
\text { VIVI } \\
\text { Local } \\
\text { Rates }\end{array}$ & $\begin{array}{c}\text { pseudo } \\
\text { conc } \\
\text { VIVI } \\
\text { Overall } \\
\text { Rates } \\
\end{array}$ & VI & $\begin{array}{l}\text { conc } \\
\text { VIVI } \\
\text { Local } \\
\text { Rates }\end{array}$ & $\begin{array}{c}\text { conc } \\
\text { VIVI } \\
\text { Overall } \\
\text { Rates }\end{array}$ & VI \\
\hline 2455 & $\begin{array}{l}\text { green } \\
\text { white }\end{array}$ & 55.6 & $\begin{array}{l}52.9 \\
53.1\end{array}$ & 55.0 & $\begin{array}{l}45.8 \\
47.7\end{array}$ & 56.3 & $\begin{array}{r}0.0 \\
62.4\end{array}$ & $\begin{array}{r}0.0 \\
62.3\end{array}$ & 61.1 & $\begin{array}{l}58.6 \\
68.1\end{array}$ & $\begin{array}{l}57.6 \\
13.5\end{array}$ & 61.7 \\
\hline 2560 & $\begin{array}{l}\text { green } \\
\text { white }\end{array}$ & 54.0 & $\begin{array}{l}47.7 \\
49.2\end{array}$ & 51.8 & $\begin{array}{l}48.1 \\
53.0\end{array}$ & 56.2 & $\begin{array}{r}0.0 \\
61.9\end{array}$ & $\begin{array}{r}0.0 \\
60.6\end{array}$ & 60.1 & $\begin{array}{r}72.9 \\
189.2\end{array}$ & $\begin{array}{l}57.4 \\
42.4\end{array}$ & 60.2 \\
\hline 2457 & $\begin{array}{l}\text { green } \\
\text { white }\end{array}$ & 50.8 & $\begin{array}{l}39.8 \\
39.7\end{array}$ & 48.0 & $\begin{array}{l}43.9 \\
45.6\end{array}$ & 52.4 & $\begin{array}{l}55.3 \\
67.9\end{array}$ & $\begin{array}{r}54.4 \\
1.1\end{array}$ & 36.9 & $\begin{array}{r}53.9 \\
0.0\end{array}$ & $\begin{array}{r}53.9 \\
0.0\end{array}$ & 45.0 \\
\hline 2454 & $\begin{array}{l}\text { green } \\
\text { white }\end{array}$ & 51.8 & $\begin{array}{l}51.7 \\
52.1\end{array}$ & 52.3 & $\begin{array}{l}47.3 \\
46.5\end{array}$ & 52.2 & $\begin{array}{l}61.6 \\
55.4\end{array}$ & $\begin{array}{r}52.2 \\
8.5\end{array}$ & 59.5 & $\begin{array}{r}366.4 \\
60.3\end{array}$ & $\begin{array}{l}33.5 \\
55.8\end{array}$ & 61.2 \\
\hline mean & $\begin{array}{l}\text { green } \\
\text { white }\end{array}$ & 53.1 & $\begin{array}{l}48.0 \\
48.5\end{array}$ & 51.8 & $\begin{array}{l}46.3 \\
48.2 \\
\end{array}$ & 54.3 & $\begin{array}{l}29.2 \\
61.9 \\
\end{array}$ & $\begin{array}{l}26.6 \\
33.1 \\
\end{array}$ & 54.4 & $\begin{array}{r}137.9 \\
79.4 \\
\end{array}$ & $\begin{array}{l}50.6 \\
27.9 \\
\end{array}$ & 57.0 \\
\hline
\end{tabular}


the failure of the prediction for the concurrent schedules. As argued earlier, the increase in the total rate of reinforcement from approximately 60 to 120 reinforcers $/ \mathrm{h}$ might have produced an increase in the rate of responding large enough to disguise the decrease in the rate of responding predicted by the equation. If this were so, then eliminating the change in the total rate of reinforcement should have revealed the predicted decrease in response rates. The total rate of reinforcement did not change systematically when subjects moved from the VI to the pseudoconcurrent schedule. In fact, the sum of the overall rates of reinforcement obtained from the components of the pseudoconcurrent schedule were almost exactly equal to the rates of reinforcement obtained from the VI schedules which followed them, for three of the four subjects. But a decrease in response rate did not occur for this transition.

Second, the failure of the prediction for the concurrent schedules did not occur because the $m$ parameter was very small. As argued earlier, large changes in $\mathbf{R}_{\mathbf{2}}$ would produce no changes in $R_{1}+\mathbf{m R}_{\mathbf{2}}+\mathbf{R}_{\mathbf{0}}$ if $m$ were approximately 0 . The rate of responding would not change if $R_{1}+m_{2}+R_{0}$ did not change. But Herrnstein's theory explicitly states that $\mathrm{m}=1.0$ for concurrent schedules (Herrnstein, 1970). Thus, the theory would have to be revised if this explanation for the present results proved correct.

Third, the failure of the predictions for concurrent schedules probably did not occur because the change in $\mathbf{R}_{\mathbf{2}}$ was too small to detect. $\mathbf{R}_{\mathbf{2}}$ refers to the rate of reinforcement obtained by the subjects, not to the rate programmed by the experimenter. $\mathbf{R}_{2}$ would be small if the subject rarely responded on the second component schedule, regardless of the rate of reinforcement scheduled by the experimenter. Table 3 shows that $R_{2}$ did equal 0 for one of the subjects responding on the concurrent schedule. Herrnstein's equation would not predict a change in $P_{1}$ for this subject. But it may be asked if the changes in $\mathbf{R}_{\mathbf{2}}$ were large enough to produce detectable changes in $P_{1}$ for the other three subjects.

The size of the change in $P_{1}$ which would be expected when $R_{2}$ changed by the amounts shown in Table 3 cannot be predicted exactly. The sizes of the $k$ and $R_{0}$ parameters are not known for the present subjects. But an estimate of the size of these parameters may be based on the results of past studies. Past results suggest that $\mathbf{k}$ may be approximately 100 pecks/min and $R_{0}$ approximately 10 reinforcers $/ h$ for pigeons pecking keys for food reinforcement while maintained at $80 \%$ to $85 \%$ of their free-feeding weight (Herrnstein, 1970). Substituting these values into Equation 1 suggests that the size of the change in $P_{1}$, produced when the subjects moved from the VI to the concurrent schedule, should have been at least 20 responses/min for the three subjects which did obtain reinforcement from the second component. Changes in the rate of responding of this magnitude should be easily detectable.

Fourth, changes in the size of the $\mathbf{R}_{\mathbf{0}}$ parameter should not have produced failure of the prediction for the concurrent schedules. The predicted rates of responding would not change if a decrease in the size of $\mathbf{R}_{\mathbf{0}}$ compensated for the increase in $\mathbf{R}_{\mathbf{2}}$. However, the decrease in $R_{0}$ would have to be larger than the increase in $R_{2}$ to produce the present increases in response rates. The size of $R_{0}$ probably could not decrease enough to compensate for the changes in $\mathbf{R}_{2}$ reported in Table 3 , if the $\mathbf{R}_{\mathbf{0}}$ parameters were approximately equal to 10 reinforcers $/ h$, as past results suggest they should be (Herrnstein, 1970). But, Herrnstein's interpretation of his $\mathbf{R}_{0}$ parameter would have to be revised even if $\mathbf{R}_{\mathbf{0}}$ did change. The interpretation of $R_{0}$ as reinforcers obtained spontaneously from unprogrammed sources does not necessarily suggest that the size of $R_{0}$ should vary inversely with changes in $R_{2}$. Thus, the theory would be incomplete even if changes in $R_{0}$ did produce the present results.

Herrnstein's prediction for multiple schedules did not fail because the change in $R_{2}$ was too small to detect. Table 3 shows that $R_{2}$ was consistently large for the multiple schedules. However, the failure may have occurred because the $\mathrm{m}$ parameter was small. Substituting values of $\mathrm{k}$ equal to 100 responses $/ \mathrm{min}$ and $R_{0}$ equal to 10 reinforcers/h into Equation 1 shows that the predicted change in $P_{1}$ would be less than 12 responses/min for values of $m$ less than .2. As the $\mathrm{m}$ parameter got smaller, the predicted change in the size of $P_{1}$ would become harder to distinguish from random fluctuations in the rate of responding.

A change in the size of $R_{0}$ may have also contributed to the failure of the prediction for multiple schedules. The predicted rate of responding would not change if a decrease in the size of $\mathbf{R}_{\mathbf{0}}$ compensated for the increase in $\mathrm{mR}_{2}$ when subjects moved from the VI to the multiple schedules. The size of the decrease in $\mathbf{R}_{0}$ would have to be similar to the size of the increase in $\mathrm{mR}_{2}$ to produce the random changes in the rates of responding found for the transition to the multiple schedules. But $\mathrm{mR}_{2}$ would be less than 12 reinforcers/ $h$ if $m$ was less than .2 . The size of $\mathbf{R}_{\mathbf{0}}$ might change by this amount. Again, Herrnstein's interpretation of his $\mathbf{R}_{\mathbf{0}}$ parameter would have to be revised if $R_{0}$ did vary inversely with $\mathbf{R}_{\mathbf{2}}$.

The results for the concurrent schedule should be replicated; the generality of the results for the concurrent and multiple schedules should be determined; and the factors which produced these results should be identified. The results for the concurrent schedule 
should be replicated for two reasons. First, Herrnstein's theory makes a stronger prediction for the transition from the VI to the concurrent schedule than for the transition from the VI to the multiple schedules. The effect of introducing $R_{2}$ is not attenuated by multiplying it by an $m$ parameter with a value less than $\mathbf{1 . 0}$ for concurrent schedules. Thus, the results for the concurrent schedule should provide a better test of Herrnstein's equation. Second, the present results might not be replicated if subjects did obtain a larger rate of reinforcement from the second component of the concurrent schedule. As mentioned earlier, $R_{2}$ changed for only 3 of 4 subjects moved from the VI to the concurrent schedule. The responding of one of these subjects did show the change predicted by Herrnstein's equation: subject 2454 did respond at a lower overall rate on the component of the concurrent schedule which was signaled by the green stimulus than it did on the VI schedule which preceded or followed it. This explanation cannot account for the failure of the prediction for the other two subjects which did show large changes in the value of $\mathbf{R}_{2}$. But it should not be dismissed without an experimental test.

The generality of the results for the concurrent schedule should be extended by holding the total rate of reinforcement constant in other ways. The pseudoconcurrent schedule does not share all of the properties of a concurrent schedule. For example, standard concurrent schedules provide higher rates of reinforcement (total number of reinforcers collected divided by session time) when the subjects distribute their responding between the component schedules than when they respond on only one component. All of the reinforcers scheduled by the second schedule remain uncollected if the subjects do not respond on it. The pseudoconcurrent schedule does not have this property. The subjects can obtain the maximum rate of reinforcement by responding on one key. Conducting an experiment which presented the following schedules: VI 1-min, conc VI 2-min VI 2-min, VI 1-min, would extend the generality of the present finding to a schedule which held the total rate of reinforcement constant and maintained the other properties of concurrent schedules.

The results of such an experiment might also extend the findings of Catania (1973). Catania reported that the sum of the rates of responding was determined by the sum of the rates of reinforcement regardless of whether the reinforcers were obtained by responding on one, two, or three keys. Catania's findings would be confirmed if the rate of responding generated by the VI 1-min schedules equaled the sum of the rates of responding generated by the components of the conc VI 2-min VI 2-min schedule.

The generality of the present results should be extended by conducting a series of experiments which delivered several different rates of reinforcement on VI, concurrent, and multiple schedules. These experiments would also help to determine the factors responsible for the failure of Herrnstein's predictions. The $\mathbf{k}, \mathbf{m}$, and $\mathbf{R}_{\mathbf{0}}$ parameters could be estimated by fitting a curve to the function which relates the rate of responding to the obtained rate of reinforcement for each subject and each schedule. Systematic differences between the parameters for the different schedules would be sought. Herrnstein's interpretation of his $\mathbf{k}$ and $\mathbf{R}_{\mathbf{o}}$ parameters should be revised if either changed from schedule to schedule. The definition of a component schedule should be revised if $m$ equaled 0 for either complex schedule. A zero value of $\mathrm{m}$ would indicate that a second schedule of reinforcement, which was defined as a separate component by the experimenter, was not discriminated as a separate component by the subject. A better definition of component schedules could be reached by determining experimentally the factors which produce nonzero values of $m$. If none of the parameters change systematically from the simple to the complex schedules, then the basic mathematical structure of Herrnstein's equation must be revised.

The equipment used to schedule reinforcers did not produce the consistent decrease in the rate of reinforcement which occurred when subjects moved from the VI to the multiple schedules. The same equipment programmed the reinforcers for both schedules. And the decrease in the rate of reinforcement was replicated. If a problem with the equipment had produced the decrease during the first multiple schedule, then the same problem should have decreased the rate of reinforcement during the following VI schedule. But the rate of reinforcement increased again when the VI schedule was reintroduced.

The consistent difference in the rates of reinforcement obtained from the simple and multiple schedules may explain why several previous studies found a decrease in the rate of responding when subjects moved from a simple to a multiple schedule, but one study did not. A large decrease in the obtained rate of reinforcement should produce a detectable decrease in the rate of responding. A small decrease in reinforcement might not produce a detectable decrease. Thus, differences between the results of past studies may have been produced by differences in the size of the changes in the obtained rate of reinforcement, rather than by fundamental differences in the subject's behavior.

The differences between the rates of reinforcement obtained from the simple and complex schedules suggest that Herrnstein's theory is incomplete. The rates of reinforcement which enter Equation 1 are obtained rates. They are not the true independent variables, the rates programmed by the 
experimenter. The decrease in the obtained rates of reinforcement suggest that an additional set of equations must be written before Herrnstein's theory will describe and predict behavior. These equations relate the obtained to the programmed rates of reinforcement. Deviations of the obtained from the programmed rates of reinforcement have appeared under other circumstances (e.g., McSweeney, 1975), but they have not been studied systematically.

The changes in the subject's behavior which produced the decrease in the obtained rate of reinforcement should be identified also. The rate of reinforcement obtained from a VI schedule is usually insensitive to changes in the rate of responding, over a wide range (Catania, 1973). But a change in the rate of reinforcement would result if the pattern of responding changed. For example, the present results would be generated if the subjects responded at a constant rate during the VI schedule, but alternated periods of no responding with periods of very fast responding during the components of the multiple schedules. The rates of responding generated by the components of the multiple schedule would appear to equal the rates generated by the VI schedules because the time spent pausing would be included in the time base for measuring response rates. But the rates of reinforcement obtained from the multiple schedule would be lower than the rate obtained from the VI schedules. Subjects responding on the multiple schedules would not collect all reinforcers immediately after they became available. Reinforcers which became available during a pause would not be collected until responding resumed. Subjects responding at a steady rate on the VI schedules would collect all reinforcers quickly, producing a higher obtained rate of reinforcement. The results of Carr and Reynolds (cited in Staddon, 1974) may support part of this theory. They found that subjects paused longer after reinforcers delivered on a mult FI FI schedule than they did after reinforcers delivered on an FI schedule. These results should be replicated in a study which uses VI schedules.

If changes in the pattern of responding did pro- duce the change in the obtained rate of reinforcement, then Herrnstein's theory must be expanded in another way. Herrnstein's equation relates a molar aspect of behavior, its rate, to a molar aspect of reinforcement, its rate. It is insensitive to changes in the patterning of either variable. A theory which describes the changes in the pattern of behavior as subjects move from simple to complex schedules must be added to Herrnstein's theory if orderly changes in pattern do occur.

\section{REFERENCES}

Bloomfield, T. M. Some temporal properties of behavioral contrast. Journal of the Experimental Analysis of Behavior, $1967,10,159-164$.

Brown, P. L., \& Jenkins, H. M. Auto-shaping of the pigeon's key-peck. Journal of the Experimental Analysis of Behavior. 1968, 11, 1-8.

Catania, A. C. Self-inhibiting effects of reinforcement. Journal of the Experimental Analysis of Behavior, 1973, $19,517.526$.

Catania, A. C., \& Reynold, G. S. A quantitative analysis of the responding maintained by interval schedules of reinforcement. Journal of the Experimental Analysis of Behavior, 1968, 11, 327-383.

DEVILlieRs, P. A. Reinforcement and response rate interaction in multiple random-interval avoidance schedules. Joumal of the Experimental Analysis of Behavior, 1972, 18, 499-507.

Herrnstein, R. J. On the law of effect. Joumal of the Experimental Analysis of Behavior, 1970, 13, 243-266.

Herrnstein, R. J. Formal properties of the matching law. Journal of the Experimental Analysis of Behavior, 1974, 21. 159-164.

Herrnstein, R. J., \& Loveland, D. H. Hunger and contrast in a multiple schedule. Journal of the Experimental Analysis of Behavior, 1974, 21, 511-517.

McSweeney, F. K. Concurrent schedule responding as a function of body weight. Animal Learning \& Behavior, 1975, 3, 264-270.

SiEgEL, S. Non-parametric statistics for the behavioral sciences. New York: McGraw-Hill, 1956. Pp. 36-42.

Spealman, R. D., \& Gollub, L. R. Behavioral interactions in multiple variable-interval schedules. Journal of the Experimental Analysis of Behavior, 1974, 22, 471-481.

Staddon, J. E. R. Temporal control, attention, and memory. Psychological Review, 1974, 81, 375-391.

(Received for publication October 30, 1975; revision accepted April 26, 1976.) 